\title{
Additional Mosapride to Proton Pump Inhibitor for Gastroesophageal Reflux Disease: A Meta-Analysis
}

\author{
Toshihiro Nishizawa ${ }^{1,2}$, Kiyoto Mori ${ }^{1}$, Shuntaro Yoshida ${ }^{2,3}$, Hirotoshi Ebinuma ${ }^{1}$, \\ Osamu Toyoshima ${ }^{2,3}$ and Hidekazu Suzuki ${ }^{4, *(D)}$ \\ 1 Department of Gastroenterology and Hepatology, International University of Health and Welfare, \\ Narita Hospital, Narita 286-8520, Japan; nisizawa@kf7.so-net.ne.jp (T.N.); kmrz2000@gmail.com (K.M.); \\ ebinuma@me.com (H.E.) \\ 2 Gastroenterology, Toyoshima Endoscopy Clinic, Tokyo 157-0066, Japan; yoshidash-int@h.u-tokyo.ac.jp (S.Y.); \\ t@ichou.com (O.T.) \\ 3 Department of Gastroenterology, Graduate School of Medicine, The University of Tokyo, \\ Tokyo 113-0033, Japan \\ 4 Division of Gastroenterology and Hepatology, Department of Internal Medicine, \\ Tokai University School of Medicine, Isehara 259-1193, Japan \\ * Correspondence: hsuzuki@tokai.ac.jp; Tel.: +81-463-93-1121
}

Received: 29 May 2020; Accepted: 19 August 2020; Published: 21 August 2020

\begin{abstract}
Background and Aim: In gastroesophageal reflux disease (GERD), the additive effect of mosapride to a proton pump inhibitor (PPI) is still controversial. This meta-analysis integrated randomized controlled trials (RCTs) in which mosapride combined with a PPI was compared with a PPI alone in GERD treatment. Methods: RCTs were systematically searched with the PubMed, Cochrane library, Web of Science, and the Igaku-Chuo-Zasshi database. We combined the data from the RCTs with a random effects model, calculated the standardized mean difference (SMD) and pooled the risk difference (RD) with 95\% confidence intervals (CIs). Results: We included nine RCTs in the present meta-analysis. In the mosapride combined with PPI group, the improvement of the symptom score was significantly greater than that in the PPI alone group without significant heterogeneity (SMD: $-0.28,95 \% \mathrm{CI}:-0.45$ to $-0.12, p=0.0007)$. In the mosapride combined with PPI group, the symptom score after treatment was significantly lower than that in the PPI alone group (SMD: $-0.24,95 \% \mathrm{CI}:-0.42$ to $-0.06, p=0.007)$. Conclusions: Mosapride combined with a PPI significantly improved the reflux symptom score compared with that of PPI alone.
\end{abstract}

Keywords: mosapride; GERD; meta-analysis; PPI

\section{Introduction}

Gastroesophageal reflux disease (GERD) is often encountered in clinical practice. The characteristics are reflux symptoms such as acid regurgitation and heartburn [1-4]. The pathophysiology of GERD includes a disorder of motor function [5,6]. GERD often causes troublesome symptoms, and impairs quality of life (QOL) [7-9]. Proton pump inhibitors (PPIs) improve the QOL in GERD patients [10]. However, PPIs are sometimes ineffective against GERD.

An alternative approach to manage symptomatic GERD is to prevent acid reflux. There is a theory that prokinetic agents would be effective against GERD, because they could enhance lower oesophageal sphincter pressure, and improve oesophageal peristalsis, oesophageal acid clearance, and gastric emptying [11]. Mosapride citrate is a prokinetic drug which stimulates the 5-hydroxytryptamine 4 (5-HT4) receptor. Mosapride increases the release of acetylcholine from parasympathetic nerves and promotes gastrointestinal motility and gastric emptying. A randomized controlled trial (RCT) by Madan et al. showed that mosapride combined with a PPI exerted a more beneficial effect than PPI 
alone [12]. However, other RCTs reported a limited effect of mosapride [13-15]. In 2013, a systematic review concluded that mosapride combined with a PPI was not more effective than a PPI alone [16]. Since then, several RCTs have been conducted [17-21], and most RCTs showed that the improvement in GERD patients who received mosapride was not statistically significant, although mosapride seemed to offer a favorable result in these patients. The reason is that the sample size was not large enough to reach statistical significance. If the data from all RCTs are systematically integrated, statistically conclusive results may be achieved in the efficacy of mosapride. Therefore, we updated a meta-analysis of the RCTs evaluating the additional effect of mosapride to a PPI for GERD.

\section{Methods}

\subsection{Search Strategy}

The literature was systematically searched using the PubMed, Cochrane library, Web of Science, and the Igaku-Chuo-Zasshi database in Japan (up to May 2020) [22]. The search words in our systematic review were: (mosapride) AND (proton pump inhibitor) AND (reflux) AND (randomized). There was no limitation in language.

\subsection{Inclusion and Exclusion Criteria}

The inclusion criteria were: (1) study design: RCT; (2) participants of RCT: patients who had GERD; (3) intervention: mosapride combined with a PPI; (4) control: PPI; (5) outcome: therapeutic effect of mosapride for GERD. The exclusion criteria were: (1) non-use of PPIs by subjects in the control group; (2) meeting abstracts; (3) duplication; (4) review articles.

\subsection{Outcome Measures}

The primary outcome was improvement in the symptom scores in our meta-analysis. The secondary outcomes included the symptom scores after treatment, the response rate associated with the treatment, and the rate of adverse effects.

\subsection{Data Extraction}

We extracted the following data from the eligible RCTs: principal author, publishing year, country, details of patients (number, age, and sex), assessment method of reflux symptoms, the duration of therapy, drugs and doses for the treatment, and outcomes. The reflux symptom scores were different among the included studies. We converted the scores to a 0-10 scale. Two researchers (K.M. and T.N.) independently checked all articles for eligibility. A third reviewer (H.S.) resolved disagreements in consultation. We contacted the responding authors to clarify the details of the studies.

\subsection{Assessment of Methodological Quality}

We assessed the quality of the included literature with the risk-of-bias tool according to the Cochrane Handbook for Systematic Reviews of Interventions (version 5.1.0) [23]. Two reviewers (H.E. and O.T.) scrutinized all studies. The six items for RCT quality assessment were: (1) random sequence generation; (2) allocation concealment; (3) blinding of participants and outcome assessment; (4) assessment of incomplete outcome data; (5) completeness of outcome reporting; (6) other potential bias.

\subsection{Statistical Analysis}

We conducted statistical analysis with the Review Manager (RevMan; The Cochrane Collaboration, 2008; The Nordic Cochrane Centre, Copenhagen, Denmark) [24-26]. A random effects model and Mante-Haenszel method were used to calculate the risk difference (RD). Inverse variance for the continuous data was used to estimate the standardized mean difference (SMD) with a 95\% confidence interval (CI). Heterogeneity between the studies was assessed with Cochran's $\mathrm{Q}$ and $\mathrm{I}^{2}$ tests. A $p$ value 
$<0.1$ was considered as significant heterogeneity because the power of the $\mathrm{Q}$ test is low. An $\mathrm{I}^{2}$ score $\geq 50 \%$ was considered as a moderate level of heterogeneity [27]. A sensitivity analysis was added to evaluate the stability of this meta-analysis. We divided all eligible trials into a non-erosive GERD group and an erosive esophagitis group, and subgroup analysis was also performed. Finally, publication bias was checked by funnel plot asymmetry. Egger's regression test also examined funnel plot asymmetry [28-31].

\section{Results}

\subsection{Search Results}

Sixty-two citations were involved in the systematic review process (Figure 1). Among them, we excluded 50 studies according to the exclusion criteria (12 unrelated topics, 7 meeting abstracts, 25 duplications, 4 review articles, and 2 protocols for RCT). The remaining 12 studies were scrutinized, after which three more studies were rejected [32-34] because subjects in the control groups did not use PPIs. Finally, we included nine RCTs in our meta-analysis [12-15,17-21]. The details of the included RCTs are presented in Table 1.

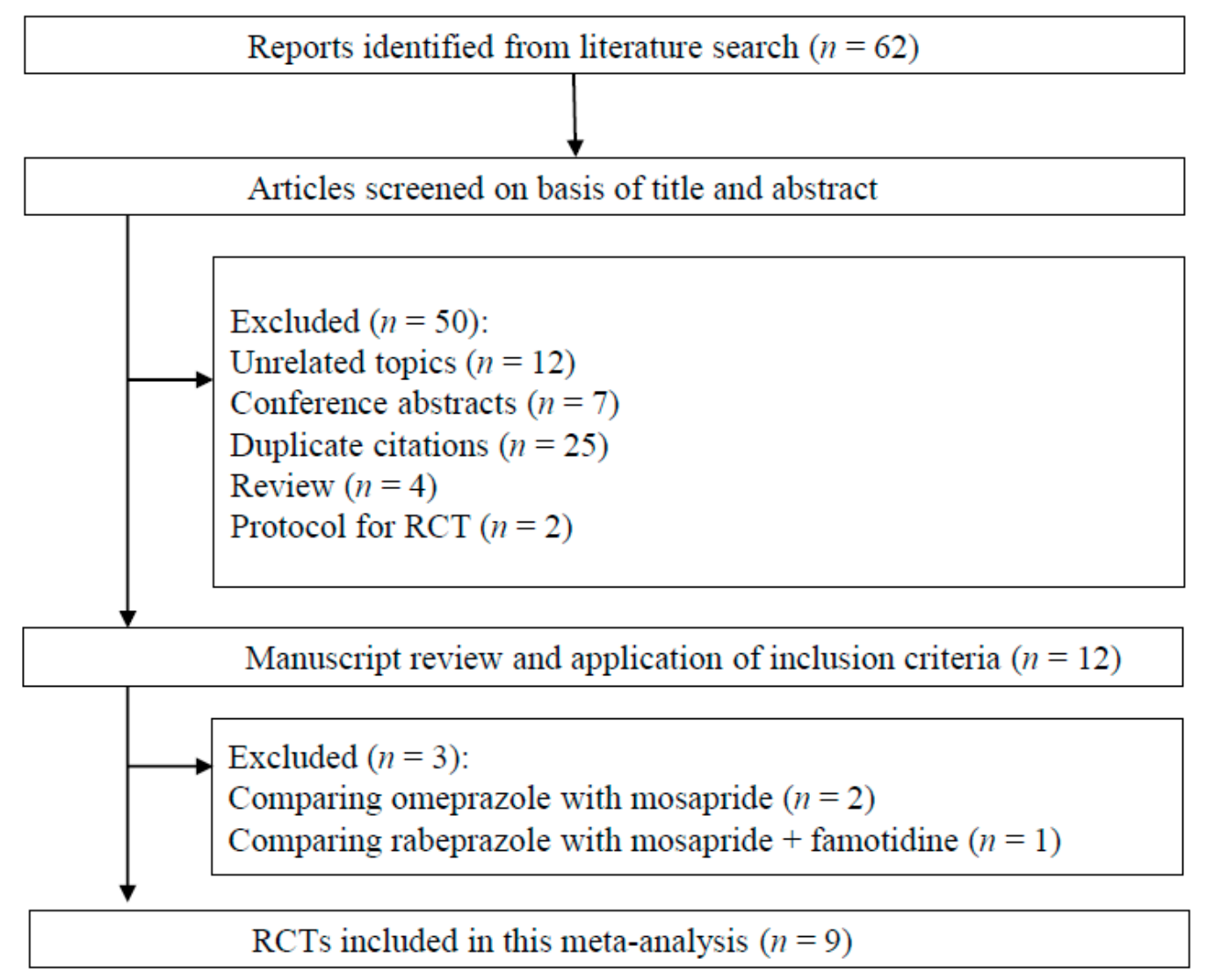

Figure 1. Flow diagram of the systematic literature search.

\subsection{Quality Assessment}

Table 2 shows the risk of bias summary. In one RCT, allocation concealment was not described. In two RCTs, the patients and the outcome assessment were not blinded. In all RCTs, the incomplete outcomes were adequately assessed, and selective outcome reporting was avoided. All RCTs did not have other biases. In general, the quality of the RCTs was very good. 
Table 1. Characteristics of studies included in the systematic review.

\begin{tabular}{|c|c|c|c|c|c|c|c|c|c|c|}
\hline Author & Country & Diagnosis of GERD & Assessment of & Range of & Duration & PPI & Allocation & Patients & Age & Gender \\
\hline & Year & & reflux symptoms & $\begin{array}{c}\text { symptom } \\
\text { score }\end{array}$ & (weeks) & (dose/day) & & number & $\pm \mathrm{SD}$ & $\mathrm{M} / \mathrm{F}$ \\
\hline \multirow[t]{2}{*}{ Madan } & India & GERD symptoms $>2 /$ week & Multiplying the scores for severity & $0-18$ & 8 & Pantoprazole & PPI & 33 & $34.7 \pm 10.8$ & 19/14 \\
\hline & 2004 & Screening endoscopy & $(0-3)$ and frequency $(0-3)$ for 2 items & & & $80 \mathrm{mg}$ & PPI + Mosapride & 28 & $36.5 \pm 12.8$ & $21 / 7$ \\
\hline \multirow[t]{2}{*}{$\mathrm{Hsu}$} & Taiwan & GERD symptoms & FSSG; sum of & $0-48$ & 4 & Lansoprazole & PPI & 46 & $47 \pm 8.9$ & $25 / 21$ \\
\hline & 2010 & Esophagitis at endoscopy & frequency $(0-4)$ for 12 items & & & $30 \mathrm{mg}$ & PPI + Mosapride & 50 & $47 \pm 14.8$ & $23 / 27$ \\
\hline \multirow[t]{2}{*}{ Miwa } & Japan & GERD symptoms >2/week & Reflux symptoms using $10-\mathrm{cm}$ & $0-10$ & 4 & Omeprazole & PPI & 95 & $52.2 \pm 15.8$ & $35 / 60$ \\
\hline & 2011 & No esophagitis at endoscopy & visual analogue scale (VAS) & & & $10 \mathrm{mg}$ & PPI + Mosapride & 97 & $52.1 \pm 16.1$ & $37 / 60$ \\
\hline \multirow[t]{2}{*}{ Lim } & Korea & Typical GERD symptoms & Severity; none (0), mild (1), & $0-3$ & 8 & Pantoprazole & PPI & 15 & $55.3(25-66) *$ & $10 / 5$ \\
\hline & 2013 & Normal gastric emptying scan & moderate (2) or severe (3) & & & $40 \mathrm{mg}$ & PPI + Mosapride & 15 & $48.5(20-70) *$ & $6 / 9$ \\
\hline \multirow[t]{2}{*}{ Cho } & Korea & GERD symptoms > 2/week & Severity; none, mild, moderate, & $1-5$ & 4 & Esomeprazole & PPI & 19 & $43 \pm 15$ & 9/10 \\
\hline & 2013 & Endoscopy, $48 \mathrm{~h} \mathrm{pH}$ monitoring & severe, or very severe & & & $40 \mathrm{mg}$ & PPI + Mosapride & 24 & $49 \pm 16$ & $15 / 9$ \\
\hline \multirow[t]{2}{*}{ Yamaji } & Japan & GERD symptoms $>2 /$ week & FSSG; sum of & $0-48$ & 4 & Omeprazole & PPI & 28 & $61.7 \pm 11.9$ & 9/19 \\
\hline & 2014 & Screening endoscopy & frequency $(0-4)$ for 12 items & & & $10 \mathrm{mg}$ & PPI + Mosapride & 22 & $65.0 \pm 11.6$ & $4 / 18$ \\
\hline \multirow[t]{2}{*}{ Lee } & Korea & GERD symptoms $>2$ /week & Multiplying the scores for severity & $0-120$ & 8 & Esomeprazole & PPI & 53 & $55.8 \pm 8.4$ & $37 / 16$ \\
\hline & 2017 & Esophagitis at endoscopy & $(0-4)$ and frequency $(0-5)$ for 6 items & & & $40 \mathrm{mg}$ & PPI + Mosapride & 56 & $54.9 \pm 11.1$ & $34 / 22$ \\
\hline Sirina & Thailand & GERD symptoms $>2$ /week & FSSG; sum of & $0-48$ & 4 & Omeprazole & PPI & 22 & $53.1 \pm 11.9$ & $6 / 16$ \\
\hline & 2019 & Screening endoscopy & frequency $(0-4)$ for 12 items & & & $20 \mathrm{mg}$ & PPI + Mosapride & 22 & $49.2 \pm 13.8$ & $7 / 15$ \\
\hline \multirow[t]{2}{*}{ Xiao } & China & GERD symptoms and cough & $\mathrm{RDQ}$; sum of frequency $(0-5)$ & $0-40$ & 12 & Omeprazole & PPI & 45 & $39.9 \pm 10.1$ & $29 / 16$ \\
\hline & 2019 & Screening endoscopy & and severity $(0-5)$ for 4 items & & & $40 \mathrm{mg}$ & PPI + Mosapride & 45 & $40.6 \pm 6.0$ & $24 / 21$ \\
\hline
\end{tabular}

GERD: gastroesophageal reflux disease, FSSG: Frequency Scale for Symptoms of GERD, RDQ: Reflux Disease Questionnaire, PPI: proton pump inhibitor, SD: standard deviation, ${ }^{*}$ range,

M/F; male/female.

Table 2. Evaluation of bias of RCTs included in the systematic review.

\begin{tabular}{cccccccc}
\hline First & $\begin{array}{c}\text { Random } \\
\text { Sequence }\end{array}$ & Allocation & $\begin{array}{c}\text { Blinding of } \\
\text { Participants }\end{array}$ & $\begin{array}{c}\text { Blinding of } \\
\text { Outcome }\end{array}$ & $\begin{array}{c}\text { Adequate } \\
\text { Assessment }\end{array}$ & $\begin{array}{c}\text { Selective } \\
\text { Reporting }\end{array}$ & No Other \\
\hline author & generation & concealment & and personnel & assessment & of incomplete & outcome & avoided \\
Madan & Yes & Yes & Yes & Yes & Yes & bias \\
Hsu & Yes & Yes & Yes & Yes & Yes & Yes & Yes \\
Miwa & Yes & Yes & Yes & Yes & Yes & Yes & Yes \\
Lim & Yes & Yes & Yes & Yes & Yes & Yes \\
Cho & Yes & Yes & Yes & Yes & Yes & Yes & Yes \\
Yamaji & Yes & Yes & No & No & Yes & Yes \\
Lee & Yes & Yes & Yes & Yes & Yes & Yes & Yes \\
Sirinawasatien & Yes & Yes & Yes & Yes & Yes & Yes & Yes \\
Xiao & Yes & Unclear & No & No & Yes & & Yes \\
\hline
\end{tabular}

Yes: Low risk of bias; No: High risk of bias; Unclear: Unclear risk of bias. 


\subsection{Meta-Analysis Results}

\subsubsection{Improvement in Symptom Scores}

A change in symptom score was described in six studies. In the mosapride combined with PPI group, the improvement of the symptom score was significantly greater than that in the PPI alone group (SMD: $-0.28,95 \%$ CI: -0.45 to $-0.12, p=0.0007$, Figure 2A). Heterogeneity was not detected between RCTs $\left(p=0.70, \mathrm{I}^{2}=0 \%\right)$. The sensitivity analysis sequentially excluded one trial at a time, and did not change the meta-analysis results.

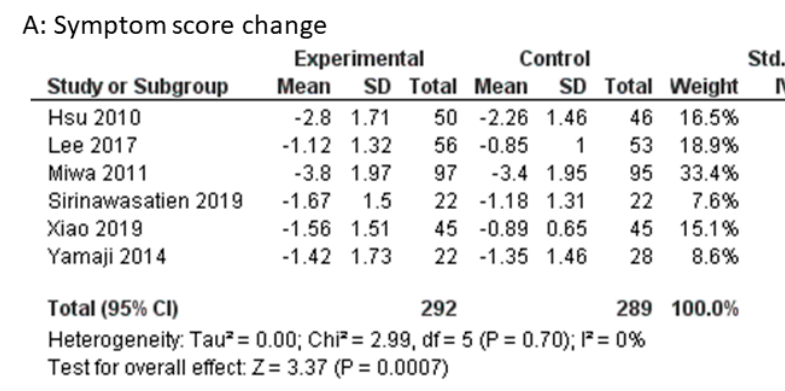

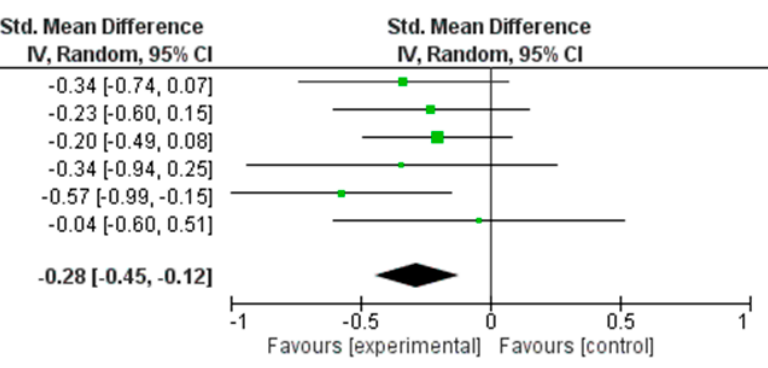

B: Symptom score after treatment

\begin{tabular}{|c|c|c|c|c|c|c|c|c|c|c|c|}
\hline \multirow[b]{2}{*}{ Study or Subgroup } & \multicolumn{3}{|c|}{ Experimental } & \multicolumn{3}{|c|}{ Control } & \multicolumn{2}{|c|}{ Std. Mean Difference } & \multirow{2}{*}{\multicolumn{3}{|c|}{$\begin{array}{c}\text { Std. Mean Difference } \\
\text { IV, Random, } 95 \% \mathrm{Cl}\end{array}$}} \\
\hline & Mean & SD & Total & Mean & SD & Total & Weight & IV, Random, $95 \% \mathrm{Cl}$ & & & \\
\hline Lee 2017 & 0.51 & 0.55 & 56 & 0.61 & 0.87 & 53 & $19.2 \%$ & $-0.14[-0.51,0.24]$ & & 5 & \\
\hline Lim 2013 & 2.23 & 0.73 & 15 & 2.19 & 0.78 & 15 & $5.8 \%$ & $0.05[-0.66,0.77]$ & & & \\
\hline Madan 2004 & 0.92 & 1.16 & 28 & 2.1 & 2.01 & 33 & $10.7 \%$ & $-0.70[-1.21,-0.18]$ & & & \\
\hline Miwa 2011 & 1.8 & 1.9 & 97 & 2.3 & 2.4 & 95 & $30.9 \%$ & $-0.23[-0.51,0.05]$ & & & \\
\hline Sirinawasatien 2019 & 2.58 & 1.55 & 22 & 2.34 & 1.46 & 22 & $8.3 \%$ & $0.16[-0.44,0.75]$ & & & \\
\hline Xiao 2019 & 2.25 & 1.51 & 45 & 2.73 & 0.22 & 45 & $15.9 \%$ & $-0.44[-0.86,-0.02]$ & & & \\
\hline Yamaji 2014 & 1.89 & 1.86 & 22 & 2.19 & 1.82 & 28 & $9.3 \%$ & $-0.16[-0.72,0.40]$ & & & \\
\hline Total $(95 \% \mathrm{Cl})$ & & & 285 & & & 291 & $100.0 \%$ & $-0.24[-0.42,-0.06]$ & & & \\
\hline $\begin{array}{l}\text { Heterogeneity: } \mathrm{Tau}^{2}= \\
\text { Test for overall effect: }\end{array}$ & $\begin{array}{l}01 ; \mathrm{Chi}^{-} \\
=2.68\end{array}$ & $\begin{array}{l}2=6.5 \\
P=0.0\end{array}$ & $\begin{array}{l}\text { 7. } d f= \\
007)\end{array}$ & $6(P=0$ & 36); $1^{2}$ & $=9 \%$ & & & $\begin{array}{c}-1 \\
\text { Favours [experimental] }\end{array}$ & Favours [co & $\begin{array}{c}1 \\
1 \\
\text { ontrol] }\end{array}$ \\
\hline
\end{tabular}

Figure 2. Forest plot of the standardized mean difference (SMD) with $95 \%$ confidence intervals (CI) for mosapride combined with PPI versus PPI alone for gastroesophageal reflux disease. (A): Symptom score change. (B): Symptom score after treatment.

\subsubsection{Symptom Scores after Treatment}

The symptom scores after treatment were described in seven studies. In the mosapride combined with PPI group, the symptom score after treatment was significantly lower than that in the PPI alone group (SMD: $-0.24,95 \% \mathrm{CI}:-0.42$ to $-0.06, p=0.007$, Figure $2 \mathrm{~B}$ ). Heterogeneity was not detected between the seven studies $\left(p=0.36, \mathrm{I}^{2}=9 \%\right)$. The sensitivity analysis sequentially excluded one trial at a time, and did not change the meta-analysis results. The funnel plot was almost symmetrical (Figure 3). Egger's regression test confirmed no evidence of substantial publication bias $(p=0.694)$.

\subsubsection{Response to Treatment}

The symptom response rates were described in three studies. Miwa et al. defined the responders as those who scored less than one on the visual analogue scale (range of 0-10). Madan et al. defined the responders as those who reported a symptom score of $\leq 4$ (range of $0-18$ ). Cho et al. defined the responders as those who had symptoms decrease from a moderately severe or greater rating, to mild or absent. Due to limited numbers, RCTs that used different criteria were included in this meta-analysis. There was no statistically significant difference in symptom response between the PPI alone group and the mosapride combined with PPI group (pooled RD: $-0.09,95 \%$ CI: -0.20 to $0.02, p=0.12$, Figure $4 \mathrm{~A}$ ). 


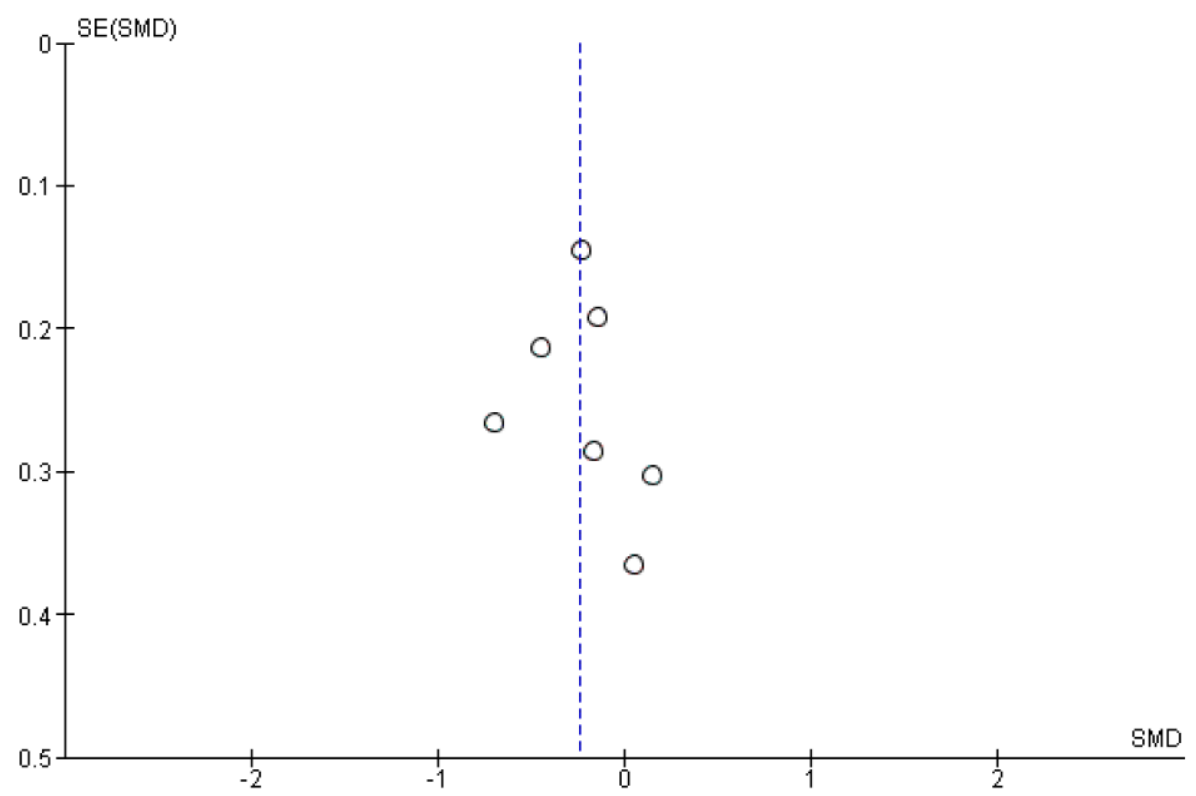

Figure 3. Funnel plot of the included RCTs for symptom score after treatment.

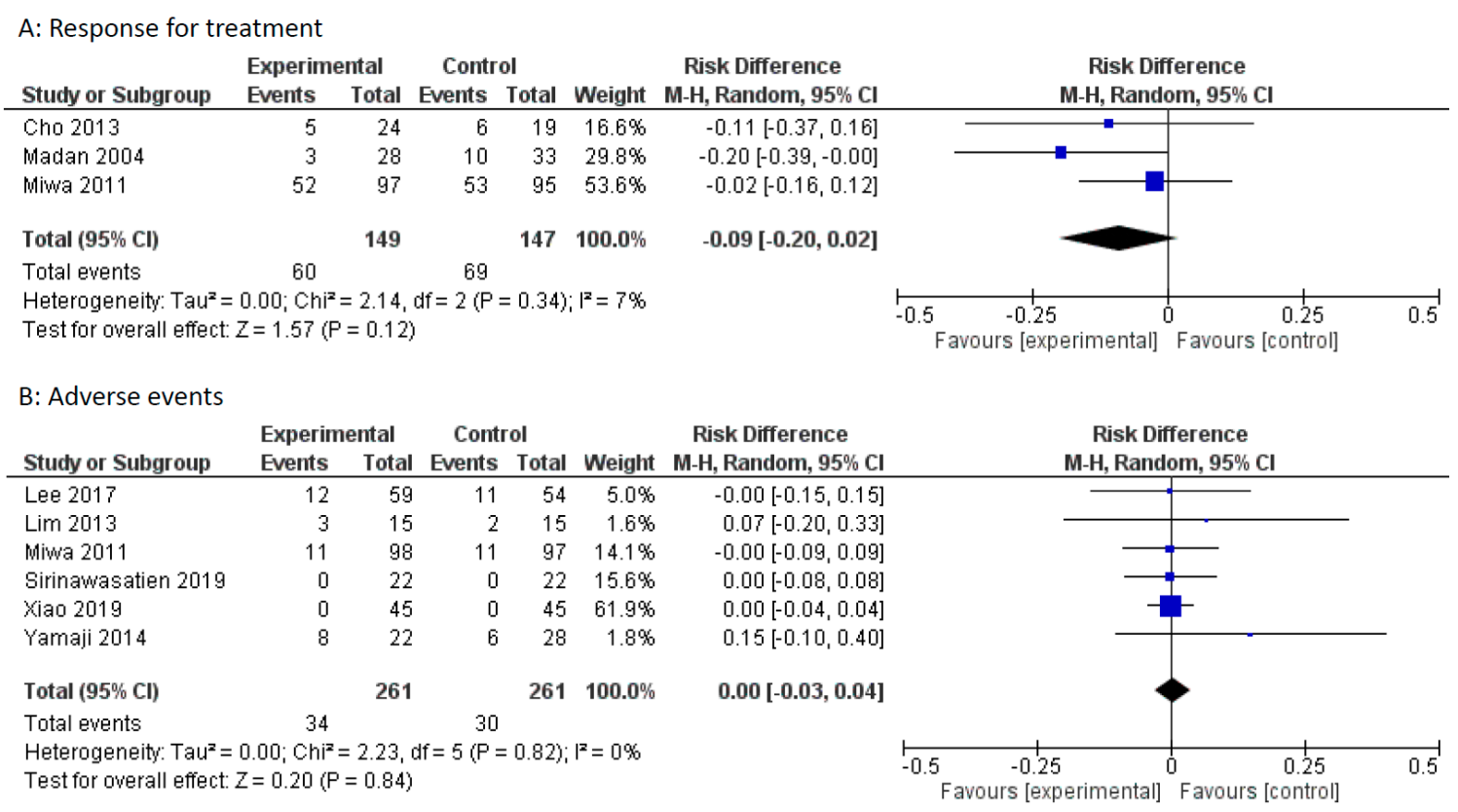

Figure 4. Forest plot of the risk difference (RD) with 95\% CI for mosapride combined with PPI versus PPI alone for gastroesophageal reflux disease. (A): Response for treatment. Events represent treatment failure. (B): Adverse events.

\subsubsection{Adverse Events}

Adverse events were described in six studies. Adverse events were similar between the PPI alone group and the mosapride combined with PPI group (pooled RD: 0.00, 95\% CI: $-0.10-0.40, p=0.84$, Figure 4B).

\subsubsection{Subgroup Analysis}

Two studies (Hsu et al. and Lee et al.) included patients with erosive esophagitis, and one study (Miwa et al.) included patients with non-erosive GERD. Madan et al. had subgroup analysis between non-erosive GERD and erosive esophagitis. In the study by Sirinawastien et al., the majority was 
non-erosive GERD (86.4\%). Subgroup analysis between non-erosive GERD and erosive esophagitis was performed in the study by Sirinawastien et al. as a non-erosive GERD study, owing to the limited number of reports. Subgroup analysis indicated that mosapride combined with a PPI significantly improved the reflux symptom score compared with that of PPI alone for the erosive esophagitis group $(p=0.05)$, but no difference was found for the non-erosive GERD group (Figure 5A,B). Furthermore, mosapride combined with a PPI significantly enhanced the response rate compared with that of PPI alone for the erosive esophagitis group $(p=0.001)$, but no difference was found for the non-erosive GERD group (Figure 5C,D).

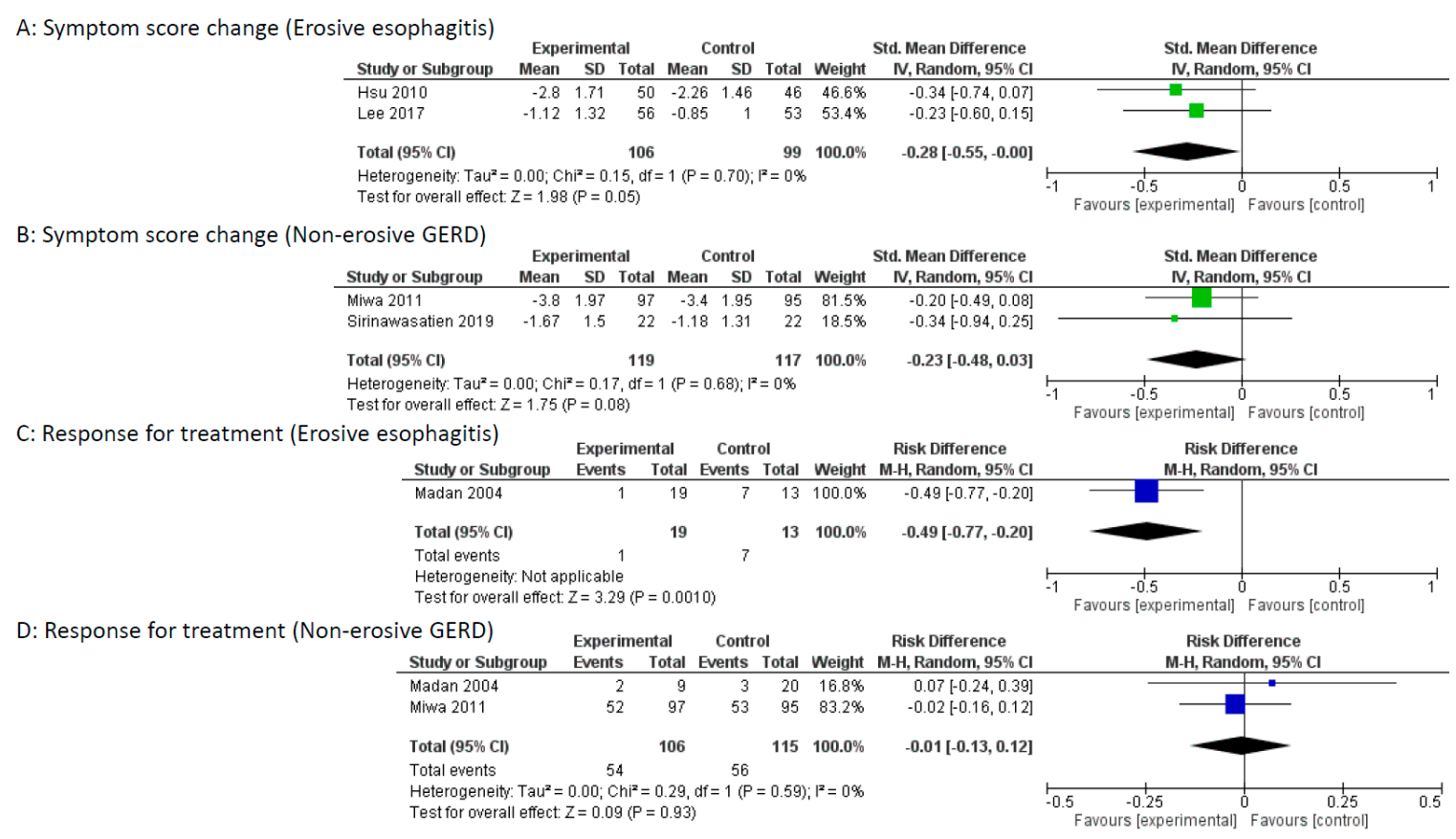

Figure 5. Subgroup analysis between non-erosive gastroesophageal reflux disease (GERD) and erosive esophagitis. (A) Forest plot of the standardized mean difference (SMD) with 95\% confidence intervals (CI) of symptom score change for mosapride combined with PPI versus PPI alone for erosive esophagitis. (B): Forest plot of the SMD with $95 \%$ CI of symptom score change for mosapride combined with PPI versus PPI alone for non-erosive GERD. (C): Forest plot of the risk difference (RD) with 95\% CI of response rate for mosapride combined with PPI versus PPI alone for erosive esophagitis. Events represent treatment failure. (D): Forest plot of the RD with $95 \% \mathrm{CI}$ of response rate for mosapride combined with PPI versus PPI alone for non-erosive GERD. Events represent treatment failure.

\section{Discussion}

Overall, we found that mosapride combined with a PPI significantly improved the reflux symptom score compared with that of PPI alone.

The previous systematic review by Liu et al. did not find any advantage of the addition of mosapride to PPIs in GERD patients [16]. The previous systematic review included four RCTs and analyzed the response rate. On the other hand, our meta-analysis included nine RCTs, and analyzed not only the response rate but also the symptom score. The response rates were described in only three studies, so did not reach significance in the previous systematic review or our meta-analysis. However, we have found that mosapride combined with a PPI significantly improved the symptom score.

5-HT4 receptor agonists include cisapride, mosapride, and tegaserod. Cisapride was on the market worldwide in the 1990s, and became popular as a prokinetic agent. In 2000, cisapride was removed from the global market because of serious cardiac adverse events [35]. Mosapride is a selective 5-HT4 receptor agonist, and has no effect on 5-HT1 and 5-HT2 receptors [16]. Mosapride does not affect 
potassium channels, as opposed to cisapride [36]. In several studies of healthy volunteers who received mosapride, no changes were detected in electrocardiogram results [37,38]. Mosapride is believed to be safe and without risk of cardiac adverse events. On the other hand, in 2007, tegaserod was removed from the market due to an increased risk of cardiovascular adverse events. In 2019, tegaserod was approved again for irritable bowel syndrome with constipation in women. However, the use is limited to women who are aged $<65$ years and who are at low risk for cardiovascular events [35].

Mosapride not only accelerates oesophageal acid clearance but may also improve the pharmacokinetics of PPIs. PPIs are unstable in gastric acid. The long retention of PPIs in the stomach could impair the acid-suppressive effect. Arai et al. showed that the pharmacokinetics of PPIs are improved by mosapride. The addition of mosapride significantly increased the area under the time-concentration curve (AUC), and the maximum plasma concentration [39]. Therefore, coadministration of mosapride could facilitate the rapid transit of PPIs into the intestine and exert better therapeutic effects.

In our subgroup analysis between non-erosive GERD and erosive esophagitis, mosapride combined with a PPI significantly improved the reflux symptom score and response rate compared with those of PPI alone for the erosive esophagitis group, but no difference was found for the non-erosive GERD group. The RCT by Madan et al. had subgroup analysis between non-erosive GERD and erosive esophagitis [12]. Mosapride combined with a PPI significantly improved the response rate compared with that of PPI alone for the erosive esophagitis group $(p=0.003)$, but no difference was found for the non-erosive GERD group. It is well known that PPIs work better in patients with erosive esophagitis than in those without erosions. Mosapride may also work better in patients with esophagitis than in those without erosions.

The cost of esomeprazole is 235 yen (\$2.2) for $40 \mathrm{mg}$ (daily dose). The cost of mosapride is 43 yen (\$0.4) for $15 \mathrm{mg}$ (daily dose). Mosapride combined with a PPI increases costs by $18 \%$. We consider that this increase in cost would be acceptable for patients receiving PPIs with incomplete symptom control.

Our meta-analysis includes several limitations. Various methods for assessment of reflux symptoms might be considered a source of heterogeneity. Various doses of PPI might also be considered a source of heterogeneity. Furthermore, we did not perform subgroup analysis for the assessment methods and PPI doses, because of the limited number of eligible RCTs. There were no European RCTs because mosapride is not available in Europe. Response rates associated with the treatment did not reach statistical significance. Future studies are needed to clarify the efficacy of mosapride for GERD.

In conclusion, the addition of mosapride to a PPI improves reflux symptoms, especially for erosive esophagitis. Mosapride could be a promising option for patients receiving acid suppression agents with incomplete symptom control.

Author Contributions: T.N., analyzed data; T.N. and H.S., wrote the manuscript; H.S., supervised the study; K.M., performed systematic literature search; S.Y., collected data; H.E. and O.T., performed quality assessment. All authors have read and agreed to the published version of the manuscript.

Funding: This research was funded by a Grant-in-Aid for Scientific Research B [20H036672, to HS], from the Japan Society for the Promotion of Science.

Conflicts of Interest: The author H.S. received scholarship funds for the research from Daiichi-Sankyo, Otsuka Pharmaceutical Co, Ltd., MSD Co., Mylan EPD, Tanabe, and Takeda Pharmaceutical Co. and received service honoraria from Astellas Pharm, Astrazeneca K.K., EA Phama Co, Ltd., Mylan EPD, Otsuka Pham, Takeda Pharm, Tsumura Co.

\section{References}

1. Boeckxstaens, G.; El-Serag, H.B.; Smout, A.J.; Kahrilas, P.J. Symptomatic reflux disease: The present, the past and the future. Gut 2014, 63, 1185-1193. [CrossRef] [PubMed]

2. Iwasaki, E.; Suzuki, H.; Sugino, Y.; Iida, T.; Nishizawa, T.; Masaoka, T.; Hosoda, H.; Kangawa, K.; Hibi, T. Decreased levels of adiponectin in obese patients with gastroesophageal reflux evaluated by videoesophagography: Possible relationship between gastroesophageal reflux and metabolic syndrome. J. Gastroenterol. Hepatol. 2008, 23, 216-221. [CrossRef] 
3. Suzuki, H.; Matsuzaki, J.; Okada, S.; Hirata, K.; Fukuhara, S.; Hibi, T. Validation of the GerdQ questionnaire for the management of gastro-oesophageal reflux disease in Japan. United Eur. Gastroenterol. J. 2013, 1, 175-183. [CrossRef] [PubMed]

4. Eguaras, N.; Rodriguez-Lopez, E.S.; Lopez-Dicastillo, O.; Franco-Sierra, M.A.; Ricard, F.; Oliva-Pascual-Vaca, A. Effects of osteopathic visceral treatment in patients with gastroesophageal reflux: a randomized controlled trial. J. Clin. Med. 2019, 8, 1738. [CrossRef] [PubMed]

5. Futagami, S.; Iwakiri, K.; Shindo, T.; Kawagoe, T.; Horie, A.; Shimpuku, M.; Tanaka, Y.; Kawami, N.; Gudis, K.; Sakamoto, C. The prokinetic effect of mosapride citrate combined with omeprazole therapy improves clinical symptoms and gastric emptying in PPI-resistant NERD patients with delayed gastric emptying. J. Gastroenterol. 2010, 45, 413-421. [CrossRef]

6. Matsuzaki, J.; Suzuki, H.; Kobayakawa, M.; Inadomi, J.M.; Takayama, M.; Makino, K.; Iwao, Y.; Sugino, Y.; Kanai, T. Association of visceral fat area, smoking, and alcohol consumption with reflux esophagitis and barrett's esophagus in Japan. PLoS ONE 2015, 10, e0133865. [CrossRef]

7. Kinoshita, Y.; Hongo, M.; Kusano, M.; Furuhata, Y.; Miyagishi, H.; Ikeuchi, S. Therapeutic response to twice-daily rabeprazole on health-related quality of life and symptoms in patients with refractory reflux esophagitis: a multicenter observational study. Intern. Med. 2017, 56, 1131-1139. [CrossRef]

8. Kwon, Y.S.; Choi, J.W.; Lee, H.S.; Kim, J.H.; Kim, Y.; Lee, J.J. Effect of a preoperative proton pump inhibitor and gastroesophageal reflux disease on postoperative nausea and vomiting. J. Clin. Med. 2020, 9, 825. [CrossRef]

9. Hirata, K.; Suzuki, H.; Matsuzaki, J.; Masaoka, T.; Saito, Y.; Nishizawa, T.; Iwasaki, E.; Fukuhara, S.; Okada, S.; Hibi, T. Improvement of reflux symptom related quality of life after Helicobacter pylori eradication therapy. J. Clin. Biochem. Nutr. 2013, 52, 172-178. [CrossRef]

10. Miwa, H.; Igarashi, A.; Teng, L.; Uda, A.; Deguchi, H.; Tango, T. Systematic review with network meta-analysis: Indirect comparison of the efficacy of vonoprazan and proton-pump inhibitors for maintenance treatment of gastroesophageal reflux disease. J. Gastroenterol. 2019, 54, 718-729. [CrossRef]

11. Ren, L.H.; Chen, W.X.; Qian, L.J.; Li, S.; Gu, M.; Shi, R.H. Addition of prokinetics to PPI therapy in gastroesophageal reflux disease: A meta-analysis. World J. Gastroenterol. 2014, 20, 2412-2419. [CrossRef] [PubMed]

12. Madan, K.; Ahuja, V.; Kashyap, P.C.; Sharma, M.P. Comparison of efficacy of pantoprazole alone versus pantoprazole plus mosapride in therapy of gastroesophageal reflux disease: A randomized trial. Dis. Esophagus 2004, 17, 274-278. [CrossRef] [PubMed]

13. Hsu, Y.C.; Yang, T.H.; Hsu, W.L.; Wu, H.T.; Cheng, Y.C.; Chiang, M.F.; Wang, C.S.; Lin, H.J. Mosapride as an adjunct to lansoprazole for symptom relief of reflux oesophagitis. Br. J. Clin. Pharm. 2010, 70, 171-179. [CrossRef]

14. Miwa, H.; Inoue, K.; Ashida, K.; Kogawa, T.; Nagahara, A.; Yoshida, S.; Tano, N.; Yamazaki, Y.; Wada, T.; Asaoka, D.; et al. Randomised clinical trial: Efficacy of the addition of a prokinetic, mosapride citrate, to omeprazole in the treatment of patients with non-erosive reflux disease-a double-blind, placebo-controlled study. Aliment. Pharm. Ther. 2011, 33, 323-332. [CrossRef] [PubMed]

15. Cho, Y.K.; Choi, M.G.; Park, E.Y.; Lim, C.H.; Kim, J.S.; Park, J.M.; Lee, I.S.; Kim, S.W.; Choi, K.Y. Effect of mosapride combined with esomeprazole improves esophageal peristaltic function in patients with gastroesophageal reflux disease: A study using high resolution manometry. Dig. Dis. Sci. 2013, 58, 1035-1041. [CrossRef]

16. Liu, Q.; Feng, C.C.; Wang, E.M.; Yan, X.J.; Chen, S.L. Efficacy of mosapride plus proton pump inhibitors for treatment of gastroesophageal reflux disease: A systematic review. World J. Gastroenterol. 2013, 19, 9111-9118. [CrossRef]

17. Lim, H.C.; Kim, J.H.; Youn, Y.H.; Lee, E.H.; Lee, B.K.; Park, H. Effects of the addition of mosapride to gastroesophageal reflux disease patients on proton pump inhibitor: A prospective randomized, double-blind study. J. Neurogastroenterol. Motil. 2013, 19, 495-502. [CrossRef]

18. Sirinawasatien, A.; Kantathavorn, N. Efficacy of the four weeks treatment of omeprazole plus mosapride combination therapy compared with that of omeprazole monotherapy in patients with proton pump inhibitor-refractory gastroesophageal reflux disease: A randomized controlled trial. Clin. Exp. Gastroenterol. 2019, 12, 337-347. [CrossRef] 
19. Yamaji, Y.; Isomura, Y.; Yoshida, S.; Yamada, A.; Hirata, Y.; Koike, K. Randomized controlled trial comparing the efficacy of mosapride plus omeprazole combination therapy to omeprazole monotherapy in gastroesophageal reflux disease. J. Dig. Dis. 2014, 15, 469-476. [CrossRef]

20. Lee, J.Y.; Kim, S.K.; Cho, K.B.; Park, K.S.; Kwon, J.G.; Jung, J.T.; Kim, E.Y.; Jang, B.I.; Lee, S.H.A. Double-blind, randomized, multicenter clinical trial investigating the efficacy and safety of esomeprazole single therapy versus mosapride and esomeprazole combined therapy in patients with esophageal reflux disease. J. Neurogastroenterol. Motil. 2017, 23, 218-228. [CrossRef]

21. Xiao, F.; Mao, J. Treatment of gastoesophageal reflux-related cough with proton pump inhibitors and prokinetic agents. Acta. Med. Mediterr. 2019, 35, 3131-3137.

22. Nishizawa, T.; Suzuki, H.; Akimoto, T.; Maehata, T.; Morizane, T.; Kanai, T.; Yahagi, N. Effects of preoperative proton pump inhibitor administration on bleeding after gastric endoscopic submucosal dissection: A systematic review and meta-analysis. United Eur. Gastroenterol. J. 2016, 4, 5-10. [CrossRef] [PubMed]

23. Higgins, J.; Green, S. Cochrane Handbook for Systematic Reviews of Interventions, Version 5.1.0 [updated March 2011]; The Cochrane Collaboration: Hoboken, NJ, USA, 2011; Available online: www.cochrane-handbook.org. (accessed on 20 March 2011).

24. Murata, M.; Sugimoto, M.; Mizuno, H.; Kanno, T.; Satoh, K. Clarithromycin versus metronidazole in first-line helicobacter pylori triple eradication therapy based on resistance to antimicrobial agents: meta-analysis. J. Clin. Med. 2020, 9, 543. [CrossRef] [PubMed]

25. Horibe, M.; Nishizawa, T.; Suzuki, H.; Minami, K.; Yahagi, N.; Iwasaki, E.; Kanai, T. Timing of oral refeeding in acute pancreatitis: A systematic review and meta-analysis. United Eur. Gastroenterol. J. 2016, 4, 725-732. [CrossRef] [PubMed]

26. Nishizawa, T.; Suzuki, H.; Higuchi, H.; Ebinuma, H.; Toyoshima, O. Effects of encircled abdominal compression device in colonoscopy: A meta-analysis. J. Clin. Med. 2019, 9, 11. [CrossRef]

27. Nishizawa, T.; Suzuki, H.; Sagara, S.; Kanai, T.; Yahagi, N. Dexmedetomidine versus midazolam for gastrointestinal endoscopy: A meta-analysis. Dig. Endosc. 2015, 27, 8-15. [CrossRef]

28. Nishizawa, T.; Suzuki, H.; Goto, O.; Ogata, H.; Kanai, T.; Yahagi, N. Effect of prophylactic clipping in colorectal endoscopic resection: A meta-analysis of randomized controlled studies. United Eur. Gastroenterol. J. 2017, 5, 859-867. [CrossRef]

29. Egger, M.; Davey Smith, G.; Schneider, M.; Minder, C. Bias in meta-analysis detected by a simple, graphical test. B.M.J. 1997, 315, 629-634. [CrossRef]

30. Ng, Q.X.; Soh, A.Y.S.; Loke, W.; Venkatanarayanan, N.; Lim, D.Y.; Yeo, W.S. A meta-analysis of the clinical use of curcumin for irritable bowel syndrome (IBS). J. Clin. Med. 2018, 7, 298. [CrossRef]

31. Nishizawa, T.; Suzuki, H.; Fujimoto, A.; Ochiai, Y.; Kanai, T.; Naohisa, Y. Effects of carbon dioxide insufflation in balloon-assisted enteroscopy: A systematic review and meta-analysis. United Eur. Gastroenterol. J. 2016, 4, 11-17. [CrossRef]

32. Sakurai, K.; Nagahara, A.; Inoue, K.; Akiyama, J.; Mabe, K.; Suzuki, J.; Habu, Y.; Araki, A.; Suzuki, T.; Satoh, K.; et al. Efficacy of omeprazole, famotidine, mosapride and teprenone in patients with upper gastrointestinal symptoms: An omeprazole-controlled randomized study (J-FOCUS). BMC Gastroenterol. 2012, 12, 42. [CrossRef] [PubMed]

33. Sakaguchi, M.; Takao, M.; Hashimoto, T.; Muroya, M.; Muroya, M.; Mashima, K.; Kiyota, K.; Shiomi, M. Efficacy of acid secretion inhibitors for FD symptoms: Multicenter study. Dig. Med. 2009, 48, 430-438.

34. Konda, Y.; Iwano, M.; Chiba, T. Comparison of PPI and prokinetics for patients with non erosive reflux disease. Dign. Treat. 2007, 95, 149-152.

35. Tack, J.; Camilleri, M.; Chang, L.; Chey, W.D.; Galligan, J.J.; Lacy, B.E.; Muller-Lissner, S.; Quigley, E.M.; Schuurkes, J.; De Maeyer, J.H.; et al. Systematic review: Cardiovascular safety profile of 5-HT(4) agonists developed for gastrointestinal disorders. Aliment. Pharm. 2012, 35, 745-767. [CrossRef]

36. Carlsson, L.; Amos, G.J.; Andersson, B.; Drews, L.; Duker, G.; Wadstedt, G. Electrophysiological characterization of the prokinetic agents cisapride and mosapride in vivo and in vitro: Implications for proarrhythmic potential? J. Pharm. Exp. 1997, 282, 220-227.

37. Katoh, T.; Saitoh, H.; Ohno, N.; Tateno, M.; Nakamura, T.; Dendo, I.; Kobayashi, S.; Nagasawa, K. Drug interaction between mosapride and erythromycin without electrocardiographic changes. Jpn. Heart J. 2003, 44, 225-234. [CrossRef] 
38. Endo, J.; Nomura, M.; Morishita, S.; Uemura, N.; Inoue, S.; Kishi, S.; Kawaguchi, R.; Iga, A.; Ito, S.; Nakaya, Y. Influence of mosapride citrate on gastric motility and autonomic nervous function: Evaluation by spectral analyses of heart rate and blood pressure variabilities, and by electrogastrography. J. Gastroenterol. 2002, 37, 888-895. [CrossRef]

39. Arai, K.; Takeuchi, Y.; Watanabe, H.; Tsukurimichi, A.; Uchida, N.; Imawari, M. Prokinetics influence the pharmacokinetics of rabeprazole. Digestion 2008, 78, 67-71. [CrossRef]

(c) (1)

(C) 2020 by the authors. Licensee MDPI, Basel, Switzerland. This article is an open access article distributed under the terms and conditions of the Creative Commons Attribution (CC BY) license (http://creativecommons.org/licenses/by/4.0/). 